\title{
Aa. Vv., Préfaces et manifestes du XIX siècle
}

\section{Ida Merello}

\section{OpenEdition \\ Journals}

\section{Edizione digitale}

URL: http://journals.openedition.org/studifrancesi/7005

DOI: $10.4000 /$ studifrancesi.7005

ISSN: 2421-5856

\section{Editore}

Rosenberg \& Sellier

\section{Edizione cartacea}

Data di pubblicazione: 1 septembre 2010

Paginazione: 399-400

ISSN: 0039-2944

\section{Notizia bibliografica digitale}

Ida Merello, «Aa. VV., Préfaces et manifestes du xIx siècle», Studi Francesi [Online], 161 (LIV | II) | 2010, online dal 30 novembre 2015, consultato il 13 janvier 2021. URL: http://journals.openedition.org/ studifrancesi/7005 ; DOI: https://doi.org/10.4000/studifrancesi.7005

Questo documento è stato generato automaticamente il 13 janvier 2021.

\section{(c) (†)}

Studi Francesi è distribuita con Licenza Creative Commons Attribuzione - Non commerciale - Non opere derivate 4.0 Internazionale. 


\title{
Aa. Vv., Préfaces et manifestes du XIX siècle
}

\author{
Ida Merello
}

\section{NOTIZIA}

Préfaces et manifestes du XIX siècle, «Revue des sciences humaines», n²95, 3/2009, pp.

211.

1 Rendiamo conto qui degli interventi che riguardano la nostra rassegna, pur se questo snatura in parte il numero della rivista, che riveste nel suo insieme un grande interesse.

Pascal DURAND (Don et déprédations. A propos de l' "Avant-dire» au “Traité du Verbe", pp. 68-77) parte da una questione apparentemente banale (a chi si rivolge una prefazione allografa autentica?) per contestare il truismo della risposta (ai lettori) e mostrare il gioco sottile che si instaura in realtà tra L'Avant-dire di Mallarmé e il Traité du verbe di Ghil. Il gesto di offrire l'avant-dire pone immediatamente Mallarmé in un ruolo magistrale e confina Ghil a quello di discepolo; tanto più che il testo delinea per la prima volta gli aspetti centrali della sua poetica. Per questo il dono viene successivamente rifiutato da Ghil, che intende rivendicare così la piena autonomia del suo dire. La ripubblicazione da parte di Mallarmé dell'Avant-dire in Crise de vers costituisce infine una riappropriazione del dono, per evitare «déprédations». Il divorzio tra i due è così definitivamente consumato.

3 Jean-Louis CABANÈs (Les «Préfaces et manifestes littéraires» d'Edmond et Jules de Goncourt: réflexivité et distinction, pp. 135-148) mostra l'inesattezza del titolo della raccolta del 1888 dei Goncourt, che in realtà non hanno mai scritto manifesti letterari, per interrogarsi sul suo significato. È la raccolta delle préfaces a farsi manifesto - osserva l'A. - sia per il continuo tessuto teorico che si viene a creare con l'assenza dei testi di riferimento, sia per la posposizione delle préfaces più antiche rispetto alle più recenti, che si presentano come un loro inquadramento. L'A. mostra come Edmond voglia sottolineare la costanza delle ragioni critiche sue e del fratello, rivendicando la 
paternità di una "scuola realista", e la diversità rispetto a Zola in nome dell' "écriture artiste". In tal modo Edmond tenta di accreditarsi come caposcuola delle future generazioni di scrittori. Compito della critica è ora confrontare il posizionamento nel campo letterario fornito dalle préfaces con quello risultante dall'estetica delle opere, quantificando così l'effetto nuovo dovuto all'insieme della loro raccolta.

4 Jacques NoIRAY (Manifestes de l'âge naturaliste, pp. 149-164) tenta di isolare cronologicamente un'«epoca naturalista», nel periodo compreso tra la préface di Germinie Lacerteux (1864) e il Manifeste dei Cinque contro La Terre (1887), all'interno del quale abbondano i documenti teorici sia dei Goncourt che di Zola. Sceglie quindi come corpus teorico le préfaces di Germinie Lacerteux, Thérèse Raquin, Le Roman expérimental e Le manifeste des Cinq. Se il vero manifesto pare all'A. la raccolta delle Soirées de Médan, che implica una solidarietà teorica di scuola, in realtà dal punto di vista strutturale gli elementi tipici dell'atteggiamento manifestario (bilancio e programma) sono entrambi presenti nelle préfaces di Zola. Il destinatario è un pubblico accorto e ristretto, e l'A. mostra anche la capacità di Zola di spiegare le sue teorie attraverso le interviste, rivelandosi il primo a saper sfruttare abilmente i diversi media.

Jean-Nicolas ILLOUZ (Les manifestes symbolistes, pp. 165-188) vede nel connubio tra l'estetico e il politico la prerogativa del manifesto simbolista e l'inizio dell'epoca della rivoluzione permanente. Se il manifesto del simbolismo appare nel 1886, l'A. ravvisa nelle traiettorie di sguardi che si evitano nel celebre quadro di Fantin-Latour del 1872 (e forse dovrebbe contare anche il vuoto lasciato da Mérat, sostituito dal celebre bouquet) l'inizio della fine del Parnasse. L'esclusione di Mallarmé dal «Parnasse contemporain» del 1876 è invece intesa come un'allusione al capitale latente del nuovo movimento, insieme alle opere di Verlaine e Rimbaud, che feconderanno il decennio successivo. L'A. vede nella plaquette dei Poètes maudits e in À rebours i primi due fattori di coesione della nuova scuola, e prende poi in considerazione il carattere manifestario della produzione del 1886, sia a livello di préfaces che dei testi che vengono prodotti o pubblicati (come le Illuminations). Il dibattito teorico sulla natura del simbolismo non si placa peraltro neppure in quell'anno, e l'A. ha buon gioco nel mostrare la varietà dei punti di vista negli anni successivi.

6 Marie-Françoise melmouX-MonTAUBin (Le manifeste décadent, un manifeste pour rire, pp. 189-206) riflettendo sul ben noto testo di Baju e su quello di poco precedente uscito su «Le Scapin littéraire, artistique et théâtral» ne ricorda la natura polemica per constatare l'indeterminatezza del movimento. In conclusione ritiene inevitabile che un movimento avente come principale caratteristica l'autoparodia non potesse essere sorretto da una serietà programmatica. 